\title{
USING MOLYBDENUM ISOTOPES TO RECONSTRUCT MARINE REDOX CHANGE THROUGH THE END TRIASSIC MASS EXTINCTION EVENT
}

\author{
ANDREW D. BOND ${ }^{1}$, ALEX DICKSON ${ }^{2}$ AND MICHA \\ $\mathrm{RUHL}^{3}$ \\ ${ }^{1}$ Royal Holloway University of London \\ ${ }^{2}$ Royal Holloway, University of London \\ ${ }^{3}$ Trinity College Dublin \\ Presenting Author: Andrew.Bond.2014@live.rhul.ac.uk
}

Strata of the Upper Triassic and Lower Jurassic are globally defined by the pulsed extinction of numerous marine fauna and catastrophic changes to global marine ecology. These collective extinctions are referred to as the 'end Triassic mass extinction event' (ETME) and have been closely associated with the onset of large igneous province volcanism from the Central Atlantic Magmatic Province (CAMP). CAMP volcanism is thought to have caused profound changes to the global climate including terrestrial wildfires, marine acidification and widespread marine anoxia. However, despite increasing support for marine anoxia as a key factor behind the ETME, its initiation, progression and geographic extensiveness remain poorly understood. In order to better understand some of these factors Molybdenum (Mo) isotope compositions have been measured from four Tethyan sites across the Triassic-Jurassic interval, that together span the ETME. The data will be discussed in terms of the basin-scale and global progression of redox across the ETME interval. 